proper references. While no informed person would dispute the relevance or sincerity of the author's concern, the reader may justifiably feel that what we now need are realistic solutions and not yet more admonishment. My fourteen-year-old son was exaggerating no more than is normal in the young in observing, 'There is nothing here we haven't known about for a hundred years; but what shall we do about it?'

F. B. O'CONNOR

\title{
The Lives of Bats, by D. W. Yalden and P. A. Morris. David and Charles, $£ 6.50$.
}

'Of all the known species of mammal, one in five is a bat. Yet far from being everyday animals bats remain creatures of mystery, the subject of more prejudice and misinformation than almost any other group of animals.' These are the authors' opening words. The mystery has undoubtedly been due to the secretive habits of bats, preventing naturalists from making observations, so that relatively few publications have appeared in the past century, and successive generations, lacking basic information, have overlooked this fascinating group. It was only in the late 1930s that a number of people in Europe and the USA began studying bat natural history. Research gained momentum in the 1950s, but the results were published in scientific journals and general readers were still without an authoritative work.

Recognising the gap, Yalden and Morris set about the task of reviewing and digesting all bat literature and regurgitating the information in this ordered and highly readable book. They cover all aspects of bat natural history - structure and evolution, diverse food and feeding habits, mechanics of flight, hibernation, specialised reproduction and behaviour, population studies and migrations. Even the most difficult aspects to make readable and understandable, the echo-location mechanisms that bats use for navigation and feeding, are presented in a form that anyone can follow. The penultimate chapter adequately covers the interactions of bats and man, both beneficial and detrimental aspects, and describes the conservation problems facing the temperate bats particularly. Finally the established 17 families of bats are described and illustrated, and the newly discovered 18th family, described in 1974, is mentioned. Bats are predominantly tropical animals' but, as this book shows, most information has been gathered about temperate, species. Every year new species are being discovered and probably many species have died or will die out without our knowing about them, particularly in tropical forest.

Fascinating bedside reading as well as a work of reference, this book will be of interest to all types of reader from children, amateur naturalists, university students to professional bat workers.

R. E. STEBBINGS

\section{The Chemical Capture of Animals, by A. M. Harthoorn. Baillière Tindall,} $£ 9.50$.

Dr Harthoorn's second book on this subject, unlike his first The Flying Syringe, is primarily for the technician, and it is as up-to-date as is possible in a review work of this size. Although he refers to published data on the handling of captive animals, the most useful and detailed information is given in the sections on work carried out in East and South Africa by his colleagues and himself. He gives sound advice on fieldcraft in approaching animals, and there is a chapter on basic anatomy and physiology. In addition to comprehensive notes on the dose rates of drugs both in the text and in an appendix, he provides chapters on emergency treatment of the animal where necessary, and of the handler in the event of accidental injection or ingestion of the drug.

The information on syringes and projectiles appears to have been drawn largely from the manufacturers' literature, and it might have been preferable if, with his 